\title{
Aproximación al régimen jurídico de las entidades de ámbito territorial inferior al municipio de Cataluña
}

\author{
Anna Pallarès Serrano \\ Profesora Colaboradora Permanente de Derecho Administrativo \\ Universidad Rovira i Virgili
}

\begin{abstract}
Sumario: I. PLANTEAMIENTO. - II. LA DENOMINACIÓN CATALANA COMO ENTIDADES MUNICIPALES DESCENTRALIZADAS. - III. LA IMPORTANCIA DEL ESTATUTO MUNICIPAL DE CALVO SOTELO DE 1924 PARA SU CONSOLIDACIÓN.-IV. DEFINICIÓN Y CARACTERÍSTICAS QUE SE DEDUCEN DE LA NORMATIVA CATALANA. - V. LA IMPORTANCIA DEL TERRITORIO COMO ELEMENTO DEFINIDOR Y DETERMINANTE DE LAS ENTIDADES MUNICIPALES DESCENTRALIZADAS. - VI. LA SIGNIFICATIVA IMPLANTACIÓN TERRITORIAL DE LAS ENTIDADES MUNICIPALES DESCENTRALIZADAS EN ÁREAS DE MONTAÑA.-VII. LA CONSTITUCIÓN DE LAS ENTIDADES MUNICIPALES DESCENTRALIZADAS. 1. Los requisitos. 2. El procedimiento. VIII. LA MODIFICACIÓN Y LA SUPRESIÓN DE LAS ENTIDADES MUNICIPALES DESCENTRALIZADAS. 1. La iniciativa. 2. El procedimiento. 3. Las causas. -IX. EL CAMBIO DE DENOMINACIÓN DE LAS ENTIDADES MUNICIPALES DESCENTRALIZADAS. X. EL REGISTRO DE ENTIDADES LOCALES. - XI. LA ORGANIZACIÓN DE LAS ENTIDADES MUNICIPALES DESCENTRALIZADAS. 1. El órgano unipersonal. 2. El órgano colegiado. 3. El régimen de consejo abierto. - XII. LAS COMPETENCIAS DE LAS ENTIDADES MUNICIPALES DESCENTRALIZADAS.-XIII. EL RÉGIMEN DE FUNCIONAMIENTO. - XIV. LA FINANCIACIÓN. - XV. CONCLUSIONES.
\end{abstract}

\section{PLANTEAMIENTO}

Las entidades de ámbito territorial inferior al municipio se orientan a la aplicación de principios que han de guiar la actuación de la Administración Pública, de acuerdo con lo que establece el artículo 103 de la Constitución Española (CE). Nos estamos refiriendo, principalmente, a los principios de eficacia y de descentralización administrativa. A la vez, estas entidades sirven para acercar la gestión municipal a las necesidades reales de sus ciudadanos.

Creemos conveniente remarcar, desde el principio, que la entidad de ámbito territorial inferior al municipio tiene personalidad jurídica como titular de unos bienes y para la administración descentralizada de unos servicios e intereses particulares y diferenciados de un núcleo de población que se encuentra separado del núcleo principal del municipio del cual forma parte ${ }^{1}$. En coherencia

\footnotetext{
1 Como afirma RIVERo YSERn, se trata de un fenómeno de descentralización municipal que supone la transferencia de competencias del municipio a la entidad local inframunicipal. Esta descentralización podrá
} 
con esta realidad, los órganos de gobierno de las entidades de ámbito territorial inferior al municipio son representativos de su propia población y, por tanto, no son designados por el Alcalde ni por el Pleno del Ayuntamiento ${ }^{2}$.

Por otro lado, es necesario aclarar que la descentralización que significa la creación de una entidad local inframunicipal es diferente de la simple descentralización funcional propia de las Administraciones instrumentales. La entidad local inframunicipal tiene una base que, aunque también forma parte de la base municipal, es propia de ellas. Nos estamos refiriendo a las concentraciones de población, a los núcleos habitados, a los cuales la normativa otorga la iniciativa para iniciar el procedimiento para su constitución como entidad local inframunicipal. Ahora bien, es evidente que, a pesar de esta realidad, estamos ante una descentralización administrativa, no ante un ente con sustantividad política.

\section{LA DENOMINACIÓN CATALANA COMO ENTIDADES MUNICIPALES DESCENTRALIZADAS}

De acuerdo con el reparto competencial que establece el artículo 149.1.18 CE, lo primero que determina el artículo 45 de la Ley 7/1985, de 2 abril, reguladora de las Bases del Régimen Local (LRBRL), es que la regulación de las entidades de ámbito territorial inferior al municipio corresponde a las Comunidades Autónomas, y que éstas podrán utilizar para referirse a ellas la denominación tradicional existente en cada Comunidad ${ }^{3}$ o cualquier otra que establezca la normativa autonómica. Al respecto, hemos de decir que en la legislación española de régimen local estas entidades se han conocido comúnmente bajo el nombre de entidades locales menores, y que muchas leyes autonómicas han optado por esta denominación.

La regulación de estas entidades en Cataluña la encontramos en el Decreto Legislativo 2/2003, de 28 de abril, por el que se aprueba el Texto refundido de la Ley Municipal y de Régimen Local de Cataluña (TRLMC). La normativa citada ha establecido la denominación de entidades municipales descentralizadas. Con anterioridad, en la Ley 8/1987, Municipal y de Régimen Local de Cataluña, estas entidades se conocían en Cataluña bajo el nombre genérico de entidades locales menores.

\footnotetext{
ser más o menos intensa pero nunca significará la total independencia de la entidad local inframunicipal del municipio en el cual se integra. Vid. Manual de Derecho Local, Madrid, Civitas, 2003, pág. 213.

2 Vid. Alonso MAS, «Las entidades locales menores», en Domingo Zaballos (Coord.), Comentarios a la Ley Básica de Régimen Local (Ley 7/1985, de 2 de abril, Reguladora de las Bases del Régimen Local), Madrid, Civitas, 2003, pág. 811.

3 En concreto, el artículo citado se refiere a «caseríos, parroquias, aldeas, barrios, anteiglesias, concejos, pedanías, lugares anejos».
} 


\section{LA IMPORTANCIA DEL ESTATUTO MUNICIPAL DE CALVO SOTELO DE 1924 PARA SU CONSOLIDACIÓN}

La Constitución de Cádiz de 1812 significó, por un lado, romper con la realidad de que cada villa, pueblo, parroquia, lugar, comunidad etc...disfrutara de un régimen jurídico particular basado en ordenanzas y costumbres inmemoriales, $\mathrm{y}$, por otro lado, el establecimiento del diseño de un mapa municipal uniforme donde el municipio era la unidad básica de organización de las comunidades locales, sin que se contemplara la posibilidad de crear organizaciones inferiores a éste. Como norma general, se estableció que los pueblos que no superasen el número de 1.000 almas no podían tener Ayuntamiento propio y, por tanto, estas pequeñas comunidades o núcleos aislados tenían que pasar a depender de un municipio determinado, y no se contemplaba la posibilidad de que pudiesen hacer valer unos intereses diferenciados a los del municipio del cual formaban parte.

Esta situación evolucionó hacia una mayor representatividad de los intereses de las pequeñas comunidades locales. En un primer momento se utilizaron fórmulas de organización desconcentrada y, con posterioridad, se reconoció una determinada personificación a estas comunidades. En referencia a su personificación, la Ley Municipal de 1870 y la Ley de 2 de octubre de 1877 establecen la figura de los «pueblos agregados», que no tenían carácter de entidad local pero a los que se les reconocía personalidad jurídica de carácter privado para administrar directamente y de manera descentralizada los bienes - sobre todo pastos y bosques - vinculados a estos núcleos de población que no tenían Ayuntamiento.

El Estatuto Municipal de Calvo Sotelo de 1924 representa un peldaño más dentro de esta evolución, transformando el «pueblo agregado» en una Administración Pública que recibe el nombre de entidad local menor, definida como parroquia, pedanía, consejo, que dentro de un municipio constituye un núcleo separado de edificaciones formando un conjunto de personas y bienes con derechos e intereses colectivos que se diferencian de los generales del municipio. De manera que la entidad local menor tiene personalidad jurídico-pública diferenciada de la del municipio en el que se encuentra integrada y del que forma parte ${ }^{4}$.

\section{DEFINICIÓN Y CARACTERÍSTICAS QUE SE DEDUCEN DE LA NORMATIVA CATALANA}

La previsión normativa de la existencia de las entidades municipales descentralizadas determina la posibilidad de poder establecer una Administración descentralizada de las concentraciones de población, es decir de personas y

4 Vid. MENÉNDEZ GARCíA, «Las entidades de ámbito territorial inferior al Municipio», en MuÑOZ MACHADO, S. (Dir.), Tratado de Derecho Municipal, Tomo I, Madrid, Civitas, 2003, págs. 1180-1183. 
bienes, que dentro de un municipio constituyan núcleos separados, siempre que en este núcleo citado no tenga su sede el Ayuntamiento ${ }^{5}$. De esta definición creemos conveniente destacar una serie de características:

a) Se trata de concentraciones de población, es decir, de núcleos habitados. Por lo tanto, sin residentes no puede haber entidad municipal descentralizada.

b) La concentración de población se ha de ubicar dentro de un municipio. Es decir, una entidad municipal descentralizada no puede tener un territorio que pertenezca a más de un municipio.

c) La concentración de población ha de estar separada del núcleo principal. La normativa no nos indica una distancia mínima entre un núcleo y el otro.

d) La capitalidad del municipio no se puede constituir en entidad municipal descentralizada.

\section{LA IMPORTANCIA DEL TERRITORIO COMO ELEMENTO DEFINIDOR Y DETERMINANTE DE LAS ENTIDADES MUNICIPALES DESCENTRALIZADAS}

De acuerdo con la CE, que determina como entes locales de existencia necesaria el municipio, la provincia y la isla en los archipiélagos ${ }^{6}$, las entidades municipales descentralizadas tienen carácter potestativo ${ }^{7}$. Por otro lado, la normativa básica estatal diferencia entre entidades locales territoriales y otras entidades locales, y no otorga la condición de entidad local territorial a las entidades de ámbito territorial inferior al municipio ${ }^{8}$. Con relación a la regulación de las entidades objeto de nuestra atención, la legislación básica estatal, en coherencia con la falta de autonomía constitucionalmente reconocida y con el reparto competencial que establece el artículo 149.1.18 CE, remite a las leyes de las Comunidades Autónomas sobre régimen local ${ }^{9}$. Por lo tanto, hemos de analizar la normativa autonómica respectiva para conocer el posible carácter territorial de los entes objeto de estudio. Así, vemos que en el TRLMC ${ }^{10}$ se determina la

\footnotetext{
5 Vid. apartados 1 y 2 del artículo 79 TRLMC.

6 Vid. artículos 140 y 141 CE.

7 Vid. artículo 3.2.a) LBRL.

8 Vid. artículo 3 LBRL. Aunque desde el punto de vista terminológico existe una contradicción, ya que la LBRL se refiere a éstas como «entidades de ámbito territorial inferior al municipio».

9 Vid. artículo 45 LBRL.

10 En el ámbito legislativo catalán haremos referencia principalmente al TRLMC (decimos principalmente porque también mencionaremos otras normas que complementan la regulación que establece el TRLMC) que
} 
consideración de las entidades municipales descentralizadas como entes de naturaleza no territorial, al considerar únicamente como entes territoriales al municipio, la comarca y la provincia ${ }^{11}$.

Esta diferenciación entre entidades locales territoriales y otras entidades locales tiene como consecuencia inmediata el reconocimiento, desde la legislación básica estatal, a los entes locales territoriales de una serie de potestades que podrán ejercer en el ámbito de sus competencias ${ }^{12}$. De manera que es a través de la legislación autonómica que se pueden concretar las potestades de las entidades territoriales de ámbito inferior al municipio ${ }^{13}$. Así se determina en el artículo 8 TRLMC cuando, después de establecer de manera general las potestades que corresponden a los entes locales territoriales de Cataluña (municipio, comarca y provincia) en el ámbito de sus competencias, se afirma, en el apartado 3, que las citadas potestades son también aplicables a los otros entes locales no territoriales de acuerdo con lo que establezcan, en su caso, sus estatutos y teniendo en cuenta las peculiaridades siguientes: En primer lugar, la potestad tributaria se refiere exclusivamente al establecimiento de tasas y contribuciones especiales. Por lo tanto, las entidades municipales descentralizadas no podrán tener impuestos propios (artículo 156 del Real Decreto Legislativo 2/2004, de 5 de agosto, por el que se aprueba el Texto Refundido de la Ley Reguladora de las Haciendas Locales); En segundo lugar, la potestad expropiatoria no la tienen los entes no territoriales, a excepción del caso de las entidades metropolitanas que pueden ejercerla directamente en el ámbito de sus atribuciones. A consecuencia de ello, los acuerdos sobre expropiación forzosa de las entidades municipales descentralizadas han de ser ratificados por el Ayuntamiento respectivo (artículo 83.3 TRLMC). Esta realidad legislativa responde a la consideración de que solo los entes territoriales de existencia obligatoria se pueden considerar como entes primarios, y son a éstos a los que de manera originaria corresponde la atribución de las respectivas potestades administrativas. A los otros entes de creación potestativa la atribución de las potestades les viene dada de forma derivada y concreta.

Ahora bien, por todo lo que acabamos de afirmar no podemos llegar a la conclusión de que en las entidades municipales descentralizadas el territorio no sea un elemento definidor y determinante de primer orden ${ }^{14}$. Esta realidad

\footnotetext{
dedica todo el Título V a la regulación de las entidades municipales descentralizadas (vid. artículos 79 a 83 TRLMC), aunque también encontramos referencias implícitas (vid. artículo 153 TRLMC) y expresas (vid. artículos 2, 22.4.b), 52.2.b), 114.2.b) TRLMC) a estas entidades en otros artículos de otros títulos de la citada norma.

11 En concreto, el artículo 3 TRLMC establece que el municipio, la comarca y la provincia tienen naturaleza territorial y disfrutan de autonomía pera la gestión de los intereses respectivos.

12 Vid. artículo 4.1 LBRL.

13 Vid. artículo 4.2 LBRL.

14 Bajo la vigencia de la Ley de Régimen Local de 1955, el criterio de la esencialidad del territorio llevó a autores, como TORRES CURDI, a afirmar el carácter territorial de las entidades locales menores. Vid. su mo-
} 
queda reflejada en el TRLMC cuando afirma que la aprobación de la entidad municipal descentralizada comporta la determinación de los límites territoriales a los cuales se extiende su jurisdicción y la correspondiente separación del patrimonio $^{15}$.

\section{LA SIGNIFICATIVA IMPLANTACIÓN TERRITORIAL DE LAS ENTIDADES MUNICIPALES DESCENTRALIZADAS EN ÁREAS DE MONTAÑA}

En Cataluña existen actualmente cuatro entidades municipales descentralizadas en la provincia de Tarragona ${ }^{16}$, dos en la de Barcelona ${ }^{17}$ y cincuenta y dos en la provincia de Lérida $^{18}$. Como se puede deducir de esta realidad y de su carácter potestativo, estas entidades no ocupan todo el territorio de Cataluña, sino que su implantación territorial queda limitada a una determinada porción del territorio de una serie de municipios ubicados principalmente en las comarcas nor-occidentales de Cataluña. Esta distribución geográfica no es casualidad, sino que responde a que se dan las circunstancias que han justificado tradicionalmente su creación: la existencia de unos bienes que son administrados por una colectividad diferenciada.

Por otro lado, esta localización en áreas rurales, principalmente de montaña, hace que exista una desproporción entre territorio y población, con ámbitos territoriales extensos y un número de población muy bajo ${ }^{19}$.

nografía Las Entidades locales menores en el Derecho Administrativo español, Madrid, Instituto de Estudios de Administración Local, 1985, págs. 53-54.

15 Vid. artículo 80.3 TRLMC.

16 Nos referimos a las entidades municipales descentralizadas de La Canonja, Jesús, Els Muntells y Picamoixons.

17 Se trata de las entidades municipales descentralizadas de Valldoreix y San Martí de Torroella.

18 La relación por orden alfabético de las entidades municipales descentralizadas que existen en Lérida es la siguiente: Ainet de Besan, Arànser, Araós, Arcavell i la Farga de Moles, Arestui, Àreu, Arròs e Vila, Arró, Ars, Arties e Garòs, Asnurri, Aubèrt e Betlan, Bagergue, Baiasca, Bescaran, Betren, Canalda, Casau, Civís, Durro i Saraís, Escunhau e Casarilh, Espui, Fontllonga i Ametlla, Gausac, Gerb, Gessa, Guàrdia d'Ares, Isil i Alós, Josa de Cadí, Manyanet, Montenartró, Os de Civís, Pi, Pla de la Font, Raimat, Rocallaura, Sant Joan Fumat, Santa Maria de Meià, Seana, Sellui, Senet, Sorpe, Sossís, Sucs, Taús, Tornafort, Tredòs, Unha, Vila i Vall de Castellbò, Vilac, Vilamitjana, Víllec y Estana.

19 De acuerdo con los datos que maneja TORT I DONADA, «el territorio de las entidades municipales descentralizadas equivale a menos de un 5\% del total del territorio catalán, mientras que el porcentaje de población que vive en las entidades municipales descentralizadas representa solo un $0,24 \%$ del total de la población catalana (...) Como un aspecto final de esta cuestión hemos de señalar, finalmente, que la media de superficie por entidad es de unos $27 \mathrm{Km}^{2}$, cifra que podemos considerar como bastante elevada (sobretodo si la comparamos con el parámetro de población) y que es expresiva, en cierta manera, de la importancia específica que el factor territorio ha tenido y tiene en la configuración de la mayoría de estos entes». Vid. Les entitats municipals descentralitzades a Catalunya, Barcelona, Generalitat de Catalunya - Departament de la Presidència y Departament de Governació, 1993, págs. 48-49. 


\section{LA CONSTITUCIÓN DE LAS ENTIDADES MUNICIPALES DESCENTRALIZADAS}

El TRLMC prevé, de manera general, que para poder constituir estas entidades municipales descentralizadas han de concurrir, de manera simultánea, unos requisitos y se ha de seguir un procedimiento determinado.

De manera más excepcional, se prevé poder iniciar un proceso de reforma de la organización municipal20, en los ámbitos territoriales de Cataluña que lo requieran, a través de una propuesta del Gobierno que se ha de tramitar como proyecto de ley en el Parlamento, donde se determine, entre otras cuestiones, el mantenimiento de los antiguos núcleos municipales como órganos de participación territorial o como entidades municipales descentralizadas ${ }^{21}$.

\section{Los requisitos}

De acuerdo con lo que acabamos de señalar, de manera general, para poder constituir entidades municipales descentralizadas han de concurrir las siguientes condiciones de manera simultánea:

- Que la constitución de la entidad no comporte una pérdida de calidad de la prestación de los servicios generales del municipio.

- Que la entidad pueda contar con los recursos suficientes para cumplir sus atribuciones.

- Que concurran circunstancias de naturaleza geográfica, histórica, social, económica o administrativa que requieran su constitución.

Si comparamos la normativa catalana con la normativa estatal supletoria y la normativa de otras Comunidades Autónomas, en relación a la constitución de las entidades municipales descentralizadas, llagamos a la conclusión de que estamos ante una normativa restrictiva, ya que se pide que los tres requisitos se den de forma conjunta y no de forma alternativa.

\section{El procedimiento}

En referencia a la iniciativa para la constitución de estas entidades, en la LBRL se establece que ésta corresponderá de manera indistinta a la población interesada

\footnotetext{
20 En el caso que las medidas de fomento de fusiones o agregaciones municipales y de constitución de mancomunidades de municipios o la intervención de los entes supramunicipales no sean suficientes para garantizar un nivel homogéneo en la prestación de los servicios de competencia municipal, el Gobierno puede iniciar un proceso de reforma de la organización municipal a través de una propuesta que se ha de tramitar como proyecto de ley en el Parlamento de Cataluña. Vid. artículo 22 TRLMC.
}

21 Vid. artículo 22.4.b) TRLMC. 
o al Ayuntamiento correspondiente, y que este último ha de ser escuchado en todo caso. En coherencia con esta disposición, en el TRLMC se determina que cuando la iniciativa la toman la mayoría de los vecinos, el Ayuntamiento ha de adoptar el acuerdo sobre la constitución en el plazo de dos meses. Dicho plazo se ha de contar desde la presentación de la petición en el registro municipal.

Cuando se hace referencia a la mayoría de los vecinos, la normativa se refiere a los vecinos residentes en el territorio que ha de ser la base de la entidad en una mayoría del cincuenta por ciento, como mínimo, del último censo electoral de la parte del municipio correspondiente. A los efectos de tomar la iniciativa para la constitución de las entidades municipales descentralizadas, los vecinos han de constituir una comisión promotora formada, como mínimo, por un presidente o presidenta y dos vocales ${ }^{22}$.

En el caso que la iniciativa la tengan los vecinos, éstos han de presentar una petición en el registro del municipio correspondiente junto con una memoria en la que se justifique, como mínimo, la concurrencia de los requisitos señalados anteriormente y en el artículo 79 del TRLMC. La petición ha de adjuntar las firmas de los vecinos formalizadas ante el secretario del Ayuntamiento o protocolizadas notarialmente $\mathrm{y}$, también, ha de indicar las personas que forman parte de la comisión promotora mencionada. Como ya hemos manifestado, el Ayuntamiento ha de adoptar el acuerdo sobre la constitución en el plazo de dos meses, a contar desde la presentación de la petición en el registro municipal ${ }^{23}$.

El Pleno del Ayuntamiento es el órgano competente para tomar los acuerdos relativos a la creación de entidades de administración descentralizadas ${ }^{24}$ que requieren el voto favorable de dos terceras partes del número de hecho y, en todo caso, de la mayoría absoluta del número legal de miembros de la corporación ${ }^{25}$. El acuerdo municipal sobre constitución de la entidad municipal descentralizada ha de determinar las competencias que tiene que asumir la enti$\operatorname{dad}^{26}$ y el sistema de participación en los ingresos del Ayuntamiento.

Este acuerdo municipal sobre la constitución de entidades municipales descentralizadas, con independencia de quien haya iniciado el expediente, se ha de someter a información pública durante un plazo no inferior a sesenta días, a través de su exposición en el tablón de anuncios correspondiente y de su publicación en el Diario Oficial de la Generalitat de Catalunya ${ }^{27}$.

\footnotetext{
22 Vid. artículo 39.2 del Decreto 244/2007, de 6 de noviembre, por el que se regula la constitución y la demarcación territorial de los municipios, de las entidades municipales descentralizadas y de las mancomunidades de Cataluña (en adelante, Decreto 244/2007, de 6 de noviembre).

23 Vid. artículo 40.3 Decreto 244/2007, de 6 de noviembre.

24 Vid. artículo 52.2.b) TRLMC.

25 Vid. artículo 46 Decreto 244/2007, de 6 de noviembre, y artículo 114.2 TRLMC.

26 De acuerdo con lo que establece el artículo 82 TRLMC.

27 Vid. artículo 79.1 TRLMC y artículo 41.2 Decreto 244/2007, de 6 de noviembre.
} 
Una vez realizado el trámite anterior, la corporación municipal ha de remitir el expediente al Departamento de Gobernación y Administraciones Públicas, junto con la resolución de las reclamaciones o alegaciones presentadas. Esta última resolución se ha de adoptar por el Pleno con el mismo quórum establecido para tomar los acuerdos relativos a la creación, la modificación y la supresión de entidades municipales descentralizadas - el voto favorable de dos terceras partes del número de hecho y, en todo caso, de la mayoría absoluta del número legal de miembros de la corporación-. Dicha remisión también se tendrá que hacer cuando el expediente se haya iniciado a instancia de los vecinos, aunque el acuerdo municipal no haya sido favorable ${ }^{28}$.

La Dirección General de Administración Local ha de elaborar, en el plazo de dos meses, un informe sobre la procedencia de la constitución de la entidad municipal descentralizada.

Posteriormente, el Departamento de Gobernación y Administraciones Públicas ha de remitir el expediente, sucesivamente, a la Comisión de Delimitación Territorial y a la Comisión Jurídica Asesora, para que elaboren los informes correspondientes en el plazo de dos meses ${ }^{29}$.

Si el acuerdo del Ayuntamiento y los informes de las comisiones son favorables, el Gobierno de la Generalitat ha de aprobar la constitución de la entidad municipal descentralizada en el plazo de seis meses, a contar desde la recepción del expediente ${ }^{30}$. De manera que la constitución de entidades municipales descentralizadas requiere la aprobación definitiva del Gobierno de la Generalitat ${ }^{31}$.

La falta de resolución expresa, en el plazo mencionado, produce efectos estimatorios de la solicitud. Ahora bien, cuando el acuerdo del Ayuntamiento o alguno de los citados informes son desfavorables, en este caso, la falta de resolución expresa en el plazo señalado produce efectos desestimatorios ${ }^{32}$.

Aunque nos encontramos que la normativa que regula las entidades municipales descentralizadas no lo establece de manera expresa, existe la posibilidad teórica de que el Gobierno de la Generalitat apruebe la constitución de entidades municipales descentralizadas a pesar de la existencia de informes desfavorables de la Comisión de Delimitación Territorial o/y de la Comisión Jurídica Asesora. En el caso que se dé esta situación, el acuerdo del Gobierno de la Generalitat tendrá que motivarse, fundamentando la resolución que se separa del

\footnotetext{
28 Vid. artículo 41.3 Decreto 244/2007, de 6 de noviembre, y artículo 79.1 c) TRLMC.

29 Vid. artículo 42.2 Decreto 244/2007, de 6 de noviembre.

30 Vid. artículo 43.1 Decreto 244/2007, de 6 de noviembre.

31 Vid. artículo 80.1 TRLMC.

32 Vid. artículo 43.1 Decreto 244/2007, de 6 de noviembre.
} 
informe o informes respectivos ${ }^{33}$. Por otro lado, de acuerdo con el diseño procedimental que realiza la normativa analizada y con la configuración de estos entes para el establecimiento de una administración descentralizada de las concentraciones de población que dentro de un municipio constituyen núcleos separados, vemos difícil que el gobierno de la Generalitat pueda aprobar la constitución de entidades municipales descentralizadas cuando el acuerdo municipal no ha sido favorable, desde el momento que éste determina aspectos tan fundamentales como las competencias que ha de asumir la entidad y el sistema de participación en los ingresos del Ayuntamiento. A pesar de ello, parece que esta posibilidad no queda del todo bloqueada.

La denegación de la constitución de una entidad de administración descentralizada se contempla sin perjuicio de la posibilidad de constituir un órgano territorial de participación ${ }^{34}$.

\section{LA MODIFICACIÓN Y LA SUPRESIÓN DE LAS ENTIDADES MUNICIPALES DESCENTRALIZADAS}

\section{La iniciativa}

La normativa catalana establece la posibilidad de proceder a la modificación o a la supresión de las entidades municipales descentralizadas en cualquiera de los siguientes supuestos:

- A petición de la propia entidad, con audiencia previa del Ayuntamiento.

- A petición del Ayuntamiento, con audiencia previa de la entidad.

- Por acuerdo del Gobierno de la Generalitat, cuando motivos de tipo económico o administrativo lo hagan aconsejable, con consulta previa a la entidad y al Ayuntamiento ${ }^{35}$.

\section{El procedimiento}

En el primer y segundo supuesto, la petición de la entidad local correspondiente se concretará en un acuerdo que se ha de enviar al Departamento de Gobernación y Administraciones Públicas, junto con una memoria que justifique la modificación o supresión ${ }^{36}$.

\footnotetext{
33 Vid. artículo 54.1.c) LRJPAC.

34 La regulación de los órganos territoriales de participación se encuentra en los artículos 61, 63, 64 y 65 TRLMC

35 Vid. artículo 80.4 TRLMC y artículo 45.1 Decreto 244/2007, de 6 de noviembre.

36 Vid. artículo 45.2 Decreto 244/2007, de 6 de noviembre.
} 
El Pleno del Ayuntamiento es el órgano competente para tomar los acuerdos relativos a la modificación y la supresión de las entidades de administración descentralizadas ${ }^{37}$. Dichos acuerdos requieren, como en los de creación, el voto favorable de dos terceras partes del número de hecho y, en todo caso, de la mayoría absoluta del número legal de miembros de la corporación ${ }^{38}$.

En este procedimiento, como en el procedimiento previsto para la constitución de las entidades municipales descentralizadas, la Dirección General de Administración Local ha de elaborar un informe sobre la modificación o supresión en el plazo de dos meses. Posteriormente, el Departamento de Gobernación y Administraciones Públicas ha de enviar el expediente a la Comisión de Delimitación Territorial y a la Comisión Jurídica Asesora, para que elaboren los informes correspondientes en el plazo de dos meses.

Cuando el Departamento de Gobernación y Administraciones Públicas tenga los informes de las dos comisiones mencionadas ha de enviar el expediente al Gobierno de la Generalitat para que, en el plazo de seis meses desde la recepción del expediente, resuelva sobre la modificación o supresión de la entidad municipal descentralizada. La falta de resolución en el plazo mencionado produce efectos estimatorios, en el caso que el procedimiento se haya iniciado a instancia de la entidad municipal descentralizada o del Ayuntamiento, y se producirá la caducidad del mismo cuando se haya iniciado por el Gobierno ${ }^{39}$.

La supresión de una entidad de administración descentralizada se lleva a cabo sin perjuicio de la posibilidad de constituir un órgano territorial de participación ${ }^{40}$.

\section{Las causas}

La normativa catalana no establece de manera expresa los motivos que pueden justificar la modificación y la supresión de las entidades municipales descentralizadas. Nosotros entendemos que se está haciendo referencia, de manera implícita, a la posibilidad de que dejen de darse, de manera sobrevenida, algunos de los requisitos que tenían que concurrir de manera conjunta para su constitución.

\footnotetext{
37 Vid. artículo 52.2.b) TRLMC.

38 Vid. artículo 46 Decreto 244/2007, de 6 de noviembre.

39 Vid. artículo 45.5 Decreto 244/2007, de 6 de noviembre.

40 La regulación de los órganos territoriales de participación la encontramos en los artículos 61,63, 64 y 65 TRLMC.
} 


\section{EL CAMBIO DE DENOMINACIÓN DE LAS ENTIDADES MUNICIPALES DESCENTRALIZADAS}

La denominación oficial de las entidades municipales descentralizadas es la que establece el decreto del Gobierno que aprueba su constitución, y que ha de figurar inscrito en el Registro de entes locales de Cataluña.

El procedimiento para el cambio de denominación se puede iniciar a instancia de la misma entidad, del Ayuntamiento afectado o del Gobierno de la Generalitat ${ }^{41}$.

En el caso que el expediente sea iniciado por la misma entidad municipal descentralizada, el acuerdo de iniciación se ha de adoptar por la Junta de vecinos a propuesta del presidente ${ }^{42}$, y se ha de presentar al Ayuntamiento para su tramitación ${ }^{43}$.

Para elaborar la propuesta de nueva denominación, el Instituto de Estudios Catalanes (en adelante, IEC) ha de prestar la asistencia y colaboración necesarias a quien lo solicite.

En cualquier caso, y con independencia de quien tome la iniciativa para el cambio de denominación, ésta solo puede cambiar si así lo acuerda el Ayuntamiento respectivo. La tramitación es la misma que se establece para el cambio de denominación de los municipios, y consiste en el siguiente procedimiento ${ }^{44}$ :

- El Pleno del Ayuntamiento, después del trámite de información pública del expediente durante un plazo de 30 días, ha de adoptar el acuerdo inicial del cambio de denominación por mayoría absoluta del número legal de sus miembros. El acuerdo se ha de enviar al Departamento de Gobernación y Administraciones Públicas en el plazo de 15 días desde su adopción.

- El Departamento citado lo ha de remitir al IEC, que en el plazo máximo de dos meses ha de informar con relación a la adecuación o no de la nueva denominación con la toponímica catalana, su corrección lingüística o la posible confusión con la denominación de otra entidad. Si en el plazo señalado no se ha emitido el informe, éste se ha de entender favorable y continuar las actuaciones ${ }^{45}$.

\footnotetext{
41 Vid. artículo 12.1 Decreto 139/2007, de 26 de junio, por el que se regulan la denominación, los símbolos y el Registro de entes locales de Cataluña (en adelante, Decreto 139/2007, de 26 de junio).

42 Para la adopción de los acuerdos de la entidad se ha de tener en cuenta que el régimen de funcionamiento de la Junta de vecinos es el que corresponde al Pleno, en el ámbito de sus competencias. Vid. artículo 83.2 TRLMC.

43 Vid. artículo 12.2 Decreto 139/2007, de 26 de junio.

44 Vid. artículos 2 y siguientes del Decreto 139/2007, de 26 de junio.

45 No será preceptivo este informe en el caso que la nueva denominación acordada por el Ayuntamiento se adecue al criterio ya expresado por el IEC en un informe anterior.
} 
- Si el informe del IEC es favorable o éste no se ha emitido dentro del plazo establecido, el acuerdo municipal se considera definitivo y el procedimiento finaliza con una resolución del Consejero o Consejera de Gobernación y Administraciones Públicas que acreditará el cambio de denominación.

- Si el informe del IEC fuera desfavorable, el Departamento lo remitirá al Ayuntamiento para que se pronuncie en el plazo de tres meses desde su recepción. Este acuerdo municipal tendrá que ir nuevamente precedido de un trámite de información pública de 30 días y ser adoptado por la mayoría absoluta del número legal de miembros de la corporación. Si el Ayuntamiento no adopta el acuerdo en el plazo señalado se entenderá que desiste del procedimiento y se acordará su archivo por el Departamento.

- Si el nuevo acuerdo municipal se corresponde con el informe del IEC se ha de entender que aquél es definitivo y el Consejero o Consejera de Gobernación y Administraciones Públicas adoptará la resolución que acredite el cambio de denominación.

- Si el acuerdo municipal no se adecua al informe del IEC, el expediente tendrá que ser resuelto por el Gobierno de la Generalitat a propuesta del Consejero o Consejera de Gobernación y Administraciones Públicas y con audiencia previa del municipio afectado. El acuerdo del Gobierno tendrá que ser adoptado en el plazo de tres meses a contar desde la recepción del acuerdo municipal, en caso contrario el acuerdo municipal devendrá definitivo.

Los cambios de denominación de las entidades municipales descentralizadas se han de inscribir en el Registro de entes locales de Cataluña y publicarse en el Diario Oficial de la Generalitat de Cataluña. Además, el Departamento de Gobernación y Administraciones Públicas informará sobre estos cambios a la Administración del Estado, a los efectos de su anotación en el Registro general de entes locales y de su publicación en el Boletín Oficial del Estado $^{46}$.

\section{EL REGISTRO DE ENTIDADES LOCALES}

El Registro de entidades locales lo gestiona el Departamento de Gobernación y Administraciones Públicas y depende de la Dirección General de Administración Local, la cual lo he de mantener permanentemente actualizado ${ }^{47}$.

46 Vid. artículo 16 Decreto 139/2007, de 26 de junio.

47 Vid. artículo 4 TRLMC y artículo 45.2 Decreto 139/2007, de 26 de junio. 
En este Registro de carácter público se han de inscribir todos los entes locales del territorio de Cataluña ${ }^{48}$ y, por lo tanto, se han de incluir las entidades municipales descentralizadas. Esto significa que la constitución, la modificación y la supresión de las entidades municipales descentralizadas se han de anotar en el Registro de entidades locales, al igual que los cambios de denominación de dichas entidades. Además, como ya hemos constatado anteriormente, la normativa también establece que estos hechos se tendrán que publicar en el Diario Oficial de la Generalitat de Cataluña y en el Boletín Oficial del Estado ${ }^{49}$.

\section{LA ORGANIZACIÓN DE LAS ENTIDADES MUNICIPALES DESCENTRALIZADAS}

La materia organizativa y la designación de los miembros de lo órganos de las entidades municipales descentralizadas no tienen carácter básico. Por ello, el apartado 2b) del artículo 45 LBRL, que hace referencia a estas cuestiones, no goza de este carácter y, en principio, seria plenamente disponible para las Comunidades Autónomas ${ }^{50}$. Ahora bien, hemos de tener en cuenta que, por otro lado, el artículo 199 de la Ley Orgánica del Régimen Electoral General (en adelante, LOREG) establece que las normas de las Comunidades Autónomas tendrán que establecer un régimen electoral para las entidades de ámbito territorial inferior al municipio que, en todo caso, respete lo que dispone la LBRL. Debido a esta disposición orgánica, la normativa catalana no ha contradicho los preceptos del apartado 2 b) del artículo 45 LBRL, que la LOREG ha utilizado como límites para la legislación autonómica ${ }^{51}$.

Una vez aclarado el encuadre normativo, con relación a la organización de las entidades municipales descentralizadas destacamos la existencia de un órgano unipersonal y de un órgano colegiado.

\section{El órgano unipersonal}

El órgano unipersonal se denomina presidente o presidenta. Éste o ésta son elegidos directamente por los vecinos de la entidad por el sistema mayoritario,

\footnotetext{
48 Vid. artículo 4 TRLMC y artículo 45.1 Decreto 139/2007, de 26 de junio.

49 Vid. artículo 47 Decreto 244/2007, de 6 de noviembre.

50 La STC 214/1989, de 21 de diciembre, señaló, con relación al citado apartado del artículo 45 LBRL, que «al no afectar a intereses generales suprautonómicos y tratarse de una materia puramente organizativa, no puede ampararse esta normativa estatal en el concepto de base».

51 El artículo 199 de la LOREG, que regula el régimen electoral de las entidades locales de ámbito inferior al municipio, afirma: «El régimen electoral de los órganos de las entidades locales de ámbito territorial inferior al Municipio será el que establezcan las leyes de las Comunidades Autónomas que las instituyan o reconozcan, que, en todo caso, deberán respetar lo dispuesto en la Ley Reguladora de las Bases del Régimen Local...».
} 
a través de la presentación de candidatos por los diferentes partidos, federaciones, coaliciones o agrupaciones de electores. Cada candidatura a la presidencia ha de incluir un candidato o candidata suplente ${ }^{52}$.

En el supuesto de vacante en la presidencia de la entidad municipal descentralizada, el cargo ha de ser ocupado por la persona suplente de la candidatura que había obtenido más votos populares en las elecciones al órgano unipersonal. En el caso de nueva vacante, la Junta de vecinos o el Consejo general de las entidades con régimen de Consejo abierto, constituidos como comisión gestora, han de elegir el presidente o presidenta de entre sus miembros por mayoría simple.

En el caso que se produzca un empate entre diversas candidaturas, ha de ser proclamado el candidato o candidata del partido, la federación, la coalición o la agrupación de electores que había obtenido un mejor resultado electoral en el ámbito de la entidad municipal descentralizada ${ }^{53}$.

En el supuesto que no se presente ninguna candidatura en las elecciones ordinarias ni en las parciales que se hayan convocado, para cubrir la vacante existente se aplicará el mismo procedimiento que para nombrar los vocales gestores de las comisiones gestoras municipales ${ }^{54}$ teniendo en cuenta el resultado de las

52 La exigencia de incluir un candidato o candidata suplente a la candidatura a la presidencia se introduce a través de la Ley 9/2006, de 5 de julio, de modificación del artículo 81 del TRLMC.

53 Vid. artículo 81.7 TRLMC modificado a través de la Ley 9/2006, de 5 de julio, de modificación del artículo 81 del TRLMC. El artículo 81.7 del TRLMC en su anterior redacción determinaba que en el caso de vacante en la presidencia de las entidades municipales descentralizadas el cargo tenía que ser ocupado por la siguiente persona que había obtenido más votos populares en las elecciones a presidente o presidenta. Esta solución conduce a proclamar presidente o presidenta de la entidad a un candidato o candidata presentado por un partido, una federación, una coalición o una agrupación de electores que no ha sido la fuerza más votada en las elecciones iniciales. De manera que esta solución no es fiel a la correlación de las fuerzas políticas que resultan de las elecciones. Por este motivo se modifica el artículo 81.7 introduciendo una fórmula que, por un lado, continua garantizando que la presidencia de estas entidades se provea mediante la elección directa de los candidatos, y, por otro lado, determina que la persona que sustituye al presidente o presidenta ha de estar presentada por el partido, la federación, la coalición o la agrupación de electores que ha sido más votada. Además, se prevé que en caso de nueva vacante, si el método de elección previsto conduce a un empate entre diversas candidaturas, se proclamará presidente o presidenta al candidato o candidata del partido, federación, coalición o agrupación de electores que haya obtenido más buen resultado electoral en el ámbito de la entidad municipal descentralizada.

54 El citado procedimiento se determina en el artículo 7 del Decreto 78/1998, de 17 de marzo, por el que se regulan las comisiones gestoras municipales y, básicamente, consiste en:

a) El Consejero de Gobernación, de oficio o a instancia de la corporación afectada, ha de pedir a la Junta Electoral de Zona o, si esta no esta constituida, a la Junta Electoral Central, la certificación sobre los resultados electorales obtenidos por los diversos partidos políticos, federaciones, coaliciones o agrupaciones electorales en las últimas elecciones municipales realizadas en el municipio y el número de vocales que corresponde designar a cada formación política o electoral.

b) Recibida esta certificación, y en el plazo de ocho días hábiles, el Consejero de Gobernación se ha de dirigir a las citadas formaciones políticas o electorales a les cuales corresponda cubrir las vacantes de acuerdo con el resultado de las últimas elecciones municipales realizadas en el municipio, para que propongan la persona o personas que se han de integrar en la comisión gestora municipal que se ha de crear. 
últimas elecciones de la entidad municipal descentralizada ${ }^{55}$. Este procedimiento también se aplicará para cubrir la presidencia en el caso de entidades municipales descentralizadas de nueva creación hasta que no se celebren las correspondientes elecciones. En este caso, la designación se ha de realizar de acuerdo con el resultado de las últimas elecciones municipales en la sección o secciones correspondientes de la entidad municipal descentralizada de que se trate ${ }^{56}$.

\section{El órgano colegiado}

El órgano colegiado se denomina Junta de vecinos y está formado por el presidente o presidenta y por los vocales.

El número de vocales es equivalente al tercio de los concejales que integran el Ayuntamiento, que en ningún caso puede ser inferior a dos. En el caso que el número de vocales sea impar, se ha de añadir un vocal más.

La designación de vocales se hace de conformidad con los resultados de las elecciones municipales en la sección o las secciones constitutivas de la entidad. La Junta Electoral de Zona ha de determinar, de acuerdo con lo que dispone la legislación electoral, el número de vocales que corresponde a cada partido, federación, coalición o agrupación. Una vez se sabe este dato, los representantes de cada candidatura han de designar, entre los electores de cada entidad, los que han de ser vocales ${ }^{57}$.

La sustitución por vacante de los vocales de la Junta de vecinos se hace siguiendo este mismo sistema. En el caso que las formaciones políticas no designen ningún vocal, la designación corresponde al Consejero de Gobernación, con consulta previa al Consejo comarcal correspondiente ${ }^{58}$.

c) El partido político, la federación, la coalición o la agrupación electoral correspondientes han de comunicar al Consejero de Gobernación el nombre de la persona substituta en el plazo máximo de quince días hábiles, a través de un escrito en que se acredite que cumple los siguientes requisitos: 1) Tener los requisitos que exigen la normativa vigente para poder ser electores y elegibles. 2) La idoneidad adecuada o el arraigo necesarios pera el ejercicio del cargo. 3) No incurrir en ninguna causa de inelegibilidad de las que prevé la legislación electoral. El plazo máximo de quince días puede ser ampliado por la Consejería de Gobernación hasta a ocho días hábiles más, a petición de las formaciones políticas afectadas.

d) Una vez recibida la propuesta, el Consejero de Gobernación, a través de una orden que se ha de publicar en el DOGC, nombra a los vocales gestores.

e) Transcurrido el plazo establecido en el apartado c) y, si es necesario, su prórroga, sin que los vocales correspondientes hayan sido propuestos, el Consejero de Gobernación, con consulta previa al Consejo comarcal correspondiente, designa directamente los vocales entre los vecinos del municipio que reúnan los requisitos establecidos en el apartado c).

55 Vid. artículo 14.1 Decreto 78/1998, de 17 de marzo, por el que se regulan las comisiones gestoras municipales.

56 Vid. artículo 14.2 Decreto 78/1998, de 17 de marzo, por el que se regulan las comisiones gestoras municipales.

57 Vid. apartados 2, 3, 4 y 5 artículo 81 TRLMC.

58 Vid. artículo 14.3 Decreto 78/1998, de 17 de marzo, por el que se regulan las comisiones gestoras municipales. 


\section{El régimen de Consejo abierto}

La normativa determina la posibilidad de establecer el régimen de Consejo abierto para las entidades de menos de cien habitantes, las que tradicionalmente han contado con este régimen de gobierno y administración, las entidades de menos de doscientos cincuenta habitantes que disfrutan de aprovechamientos comunales con un rendimiento igual o superior a la cuarta parte de los ingresos ordinarios de su presupuesto y las que tienen características especiales que lo hacen aconsejable ${ }^{59}$.

En este supuesto, el gobierno y la administración de la entidad corresponden a un presidente o presidenta y a un Consejo general formado por todos los electores de la entidad.

Por lo tanto, en el régimen de Consejo abierto solo se ha de elegir al presidente o presidenta siguiendo lo que se ha dicho con anterioridad en el apartado de los órganos unipersonales ${ }^{60}$.

\section{LAS COMPETENCIAS DE LAS ENTIDADES MUNICIPALES DESCENTRALIZADAS}

Las competencias generales de las entidades municipales descentralizadas son:

- La vigilancia de los bienes de uso público y de los bienes comunales.

- La conservación y administración de su patrimonio, incluido el forestal, y la regulación del aprovechamiento de sus bienes comunales.

- El alumbrado público y la limpieza viaria.

- La ejecución de obras y la prestación de servicios de competencia municipal de interés exclusivo de la entidad, cuando no estén a cargo del municipio respectivo o de la comarca.

- La ordenación del tránsito de vehículos y de personas en su ámbito territorial.

- La conservación y el mantenimiento de los parques y los jardines y del patrimonio histórico y artístico de su ámbito territorial.

- Las actividades culturales y deportivas directamente vinculadas a la entidad. 
La cuarta competencia enumerada no se encuentra determinada por la normativa debido a que nos encontramos ante una cláusula abierta que se tendrá que concretar en el acuerdo municipal relativo a la constitución de la entidad municipal descentralizada. De hecho, la normativa reconoce una serie de competencias propias de las entidades municipales descentralizadas y unas posibles competencias que se tendrán que concretar en el acuerdo municipal respectivo ${ }^{61}$.

El Ayuntamiento puede delegar en la entidad municipal descentralizada competencias que permitan un ejercicio descentralizado. Para que la delegación del ejercicio de la competencia sea efectiva hace falta la aceptación de la entidad municipal descentralizada.

También se prevé la posibilidad de que administraciones locales de ámbito supramunicipal (comarca, provincia-vegueria) deleguen el ejercicio de competencias propias a entes locales de nivel inferior en el caso que afecten a los intereses de estos últimos y siempre que se mejore la eficacia de la gestión pública y se contribuya a una mayor participación ciudadana. En este caso también será necesario que el ente local delegado realice la aceptación de la delegación ${ }^{62}$.

En el supuesto que la entidad municipal descentralizada se cree en virtud de la fusión o agregación de municipios, aquella podrá prestar los servicios que gestionaba anteriormente el municipio extinguido ${ }^{63}$. Esta previsión de continuidad pretende ser un estímulo para paliar y rebajar el rechazo a la fusión o agregación de municipios por parte del ente afectado por la extinción. Por lo tanto, estamos ante otra manifestación de la utilización de las entidades municipales descentralizadas como instrumento de vertebración y ordenación del territorio.

\section{EL RÉGIMEN DE FUNCIONAMIENTO}

Al presidente o presidenta le corresponde:

- Representar la entidad.

- Administrar sus intereses.

- Ejecutar los acuerdos adoptados por la Junta de vecinos.

\footnotetext{
61 Vid. artículo 79.1.c) TRLMC.

62 Vid. artículo 153 TRLMC. En este caso, el acuerdo de delegación se ha de adoptar por mayoría absoluta del número legal de miembros de la corporación. A estas delegaciones les son aplicables las disposiciones que establece esta norma para las delegaciones de competencias de la Generalitat.
}

63 Vid. artículo 82 TRLMC. 
- Y las otras atribuciones que corresponden al Alcalde o Alcaldesa, de acuerdo con la legislación de régimen local.

El presidente o presidenta podrá asistir con voz pero sin voto a las sesiones del Ayuntamiento. El presidente o presidenta puede delegar en un vocal la asistencia a las sesiones del Ayuntamiento.

Las atribuciones y el régimen de funcionamiento de la Junta de vecinos son las que corresponden al Pleno, en el ámbito de sus competencias.

En el ámbito de sus atribuciones, las entidades municipales descentralizadas tienen plena autonomía para la administración del núcleo de población. Ahora bien, los acuerdos sobre disposición de bienes, operaciones de crédito y expropiación forzosa tendrán que ser ratificados por el Ayuntamiento en el plazo de dos meses a contar desde su remisión. La falta de acuerdo municipal dentro de este plazo produce efectos estimatorios ${ }^{64}$. La limitación de la autonomía de las entidades municipales descentralizadas con relación a estos acuerdos viene impuesta por el artículo 45.2.c) LBRL. La STC 214/1989, de 21 de diciembre, ha declarado la constitucionalidad de este acto de tutela desde el momento que se refiere a «a un catálogo tasado de supuestos de incuestionable relieve para el propio Municipio, lo que por lo mismo no coarta indebidamente la competencia de la Comunidad Autónoma".

Como manifestación de las relaciones establecidas entre el municipio y la entidad municipal descentralizada, de manera general de competencia y no de subordinación, en la normativa catalana, el TRLMC determina que los conflictos de competencia que se planteen se han de resolver por el Departamento de Gobernación y Administraciones Públicas, sin perjucio de una posterior impugnación de la resolución dictada ante la jurisdicción contenciosa administrativa ${ }^{65}$.

\section{LA FINANCIACIÓN}

El artículo 156 del Real Decreto Legislativo 2/2004, de 5 de agosto, por el que se aprueba el Texto Refundido de la Ley Reguladora de las Haciendas Locales, determina que las entidades de ámbito territorial inferior al municipio no podrán tener impuestos propios, ni podrán participar en los tributos del Estado. En cambio, si que podrán participar en los tributos del municipio al que perte-

64 Vid. apartados 1, 2, 3 y 4 del artículo 83 TRLMC.

65 Evidentemente, el artículo 176.2 TRLMC es una manifestación más del impacto del nuevo concepto de autonomía local en las relaciones interadministrativas entre una entidad municipal descentralizada y el municipio al cual pertenece. Por lo tanto, entendemos substituido el principio de subordinación por el principio de competencia. 
necen, en la proporción y con los requisitos previstos por la legislación autonómica ${ }^{66}$. La legislación catalana no realiza ninguna previsión al respecto ${ }^{67}$.

En coherencia con lo que se acaba de expresar, en el artículo 8.3 TRLMC se concreta que la potestad tributaria de estas entidades se refiere exclusivamente al establecimiento de tasas y contribuciones especiales. De manera que sus ingresos provienen, principalmente, de la participación en los tributos del municipio y de los recursos propios, que son, principalmente, las tasas, el fruto de sus bienes, las contribuciones especiales y los precios públicos que se establezcan.

\section{CONCLUSIONES}

Tradicionalmente, las entidades locales menores han servido para posibilitar la gestión descentralizada de un determinado patrimonio y de una serie de servicios de núcleos de población diseminados y apartados, situados sobre todo en el ámbito rural y, en concreto en Cataluña, en las comarcas de montaña. Como manifiesta LLISET I BORRELL «la morfología rural, unida a la existencia de un patrimonio separado, provoca los deseos de descentralización del vecindario afectado, con relación al Municipio al cual pertenece» 68 .

Aparte de que el reconocimiento de estas entidades haya respondido a la realidad acabada de mencionar, actualmente la virtualidad de esta figura reside en su utilización como instrumento de ordenación y estructuración del territorio por parte de las Comunidades Autónomas, básicamente, para dar cabida a nuevas necesidades no esencialmente patrimonialistas sino de descentralización de servicios y de reconocimiento de un marco que posibilite la gestión autónoma de los intereses de una determinada colectividad. Por lo tanto, puede tener sen-

66 El TS, interpretando esta participación de la entidad municipal descentralizada en los tributos del municipio al que pertenece, afirmaba: «Interpreta el Ayuntamiento que ello prohíbe que las entidades locales menores perciban ingresos provenientes de la participación del Municipio en los impuestos y tributos estatales, pues se alega que ello burla el espíritu de lo que dispone el precepto citado de la ley aplicable.

Frente a tal tesis, a juicio de esta Sala, debe acogerse la alegación de la entidad local menor recurrida en el sentido de que lo que prohíbe el precepto es que las entidades locales de este tipo tengan impuestos propios. Pero sobre todo, por lo que más importa en el presente proceso, debe mantenerse que es conforme a derecho la interpretación de la normativa que realiza el Tribunal a quo. Pues según éste, sin perjuicio de la prohibición de que las entidades locales menores tengan tributos propios, la segunda prohibición de que tengan participación en los impuestos estatales se refiere a una participación inmediata.

Es decir, lo que sería contrario al ordenamiento jurídico según el precepto es que se otorgasen a las entidades locales menores de forma directa participaciones en los impuestos estatales que percibe el Municipio (...). Pero nada impide por el contrario una participación mediata, esto es, que obtenida por el Municipio la participación en impuestos estatales se utilice esta fuente de ingresos municipal para la financiación de las entidades locales menores» (STS 17-1-1997).

67 Vid. artículo 83.5 TRLMC.

68 Vid. Manual de Dret Local, Barcelona, Escola d'Administració Pública de Catalunya, 1986, pág. 164. 
tido la constitución de nuevas entidades municipales descentralizadas para dar salida a estas aspiraciones sin tener que recurrir a la segregación, es decir a la creación de un nuevo municipio. Esta figura también puede ser útil para canalizar aquellas necesidades de descentralización y compensar la pérdida de la condición de municipio en el supuesto de una fusión y, por tanto, para aplicar en el ámbito territorial del municipio que desaparece.

En este último sentido, el artículo 22.4.b) TRLMC expresa que el Gobierno puede iniciar un proceso de reforma de la organización municipal en los ámbitos territoriales de Cataluña que lo requieran a través de una propuesta que se tiene que tramitar como proyecto de ley en el Parlamento de Cataluña. Esta ley de reforma, según las características de los municipios afectados, ha de determinar el mantenimiento de los antiguos núcleos municipales como órganos de participación territorial o como entidades municipales descentralizadas.

Dentro de este contexto, el artículo 82 del TRLMC establece que la entidad municipal descentralizada que se cree en el ámbito del antiguo municipio extinguido podrá prestar los servicios que gestionaba anteriormente dicho municipio. Como vemos, nos encontramos ante una manifestación de una medida incentivadora y estimuladora de la fusión o agregación de municipios o, en todo caso, ante un mecanismo que puede servir para paliar o disminuir su resistencia. 
